\title{
BMJ Open Healthcare provider perceptions of clinical prediction rules
}

\author{
Safiya Richardson, ${ }^{1}$ Sundas Khan, ${ }^{1}$ Lauren McCullagh, ${ }^{1}$ Myriam Kline, ${ }^{2}$ \\ Devin Mann, ${ }^{3}$ Thomas McGinn ${ }^{1}$
}

To cite: Richardson S,

Khan S, McCullagh L, et al. Healthcare provider perceptions of clinical prediction rules. BMJ Open 2015:5:e008461.

doi:10.1136/bmjopen-2015008461

- Prepublication history for this paper is available online. To view these files please visit the journal online (http://dx.doi.org/10.1136/ bmjopen-2015-008461).

Received 14 April 2015 Revised 11 July 2015 Accepted 4 August 2015

CrossMark

\footnotetext{
${ }^{1}$ Department of Medicine, Hofstra North Shore-LIJ School of Medicine, Manhasset, New York, USA ${ }^{2}$ Biostatistics Division, Feinstein Institute for Medical Research, Manhasset, New York, USA

${ }^{3}$ Department of Medicine, Boston University, Boston, Massachusetts, USA
}

Correspondence to Dr Sundas Khan; SKhan31@nshs.edu

\section{ABSTRACT \\ Objectives: To examine internal medicine and} emergency medicine healthcare provider perceptions of usefulness of specific clinical prediction rules.

Setting: The study took place in two academic medical centres. A web-based survey was distributed and completed by participants between 1 January and 31 May 2013.

Participants: Medical doctors, doctors of osteopathy or nurse practitioners employed in the internal medicine or emergency medicine departments at either institution.

Primary and secondary outcome measures: The primary outcome was to identify the clinical prediction rules perceived as most useful by healthcare providers specialising in internal medicine and emergency medicine. Secondary outcomes included comparing usefulness scores of specific clinical prediction rules based on provider specialty, and evaluating associations between usefulness scores and perceived characteristics of these clinical prediction rules.

Results: Of the 401 healthcare providers asked to participate, a total of $263(66 \%)$, completed the survey. The CHADS2 score was chosen by most internal medicine providers (72\%), and Pulmonary Embolism Rule-Out Criteria (PERC) score by most emergency medicine providers $(45 \%)$, as one of the top three most useful from a list of 24 clinical prediction rules. Emergency medicine providers rated their top three significantly more positively, compared with internal medicine providers, as having a better fit into their workflow $(p=0.004)$, helping more with decisionmaking ( $p=0.037)$, better fitting into their thought process when diagnosing patients $(p=0.001)$ and overall, on a 10-point scale, more useful $(p=0.009)$. For all providers, the perceived qualities of useful at point of care, helps with decision making, saves time diagnosing, fits into thought process, and should be the standard of clinical care correlated highly $(\geq 0.65)$ with overall 10-point usefulness scores.

Conclusions: Healthcare providers describe clear preferences for certain clinical prediction rules, based on medical specialty.

\section{INTRODUCTION}

Evidence-based medicine was announced as a fundamental paradigm shift in medicine in the early $1990 \mathrm{~s}$ and predicted to most useful.

\section{Strengths and limitations of this study}

- This is the first study to examine healthcare provider perceptions of usefulness of CPRs in the hospital setting.

- Providers consistently rated CHADS2, the Thrombolysis in Myocardial Infarction (TIMI) Score (NSTEMI), Wells Score for Pulmonary Embolism, Alcohol Abuse CAGE and the Ottawa Ankle Rule highly. These CPRs would be ideal candidates for integration into an electronic health record (EHR).

- Emergency medicine providers consistently rated CPRs more positively and may serve as early adapters to CPRs integrated into electronic health records.

- For all providers, the qualities of CPRs being useful at point of care and that these help with decision-making, save time diagnosing, fit well with one's thought process, and should be the standard of clinical care correlated highly $(\geq 0.65)$ with usefulness scores.

- A significant limitation of the results of this study is that mean ratings for CPR characteristics reflect only the opinion of healthcare providers who selected the CPR as one of the top three

de-emphasise intuition, clinical experience and pathophysiological rationale in favour of hard scientific evidence. ${ }^{1}$ Decades later, the accessible body of clinical research has grown exponentially, but translation into common clinical practice has been protracted and inconsistent.

The seamless integration of clinical prediction rules (CPRs) into the point of care will aid in transferring evidence-based medicine into daily clinical practice. CPRs can be defined as validated tools that quantify the individual contributions that components of history, physical and laboratory results make towards a diagnosis, prognosis or treatment response. ${ }^{2}$ A few commonly used CPRs include the CENTOR criteria, which predicts the likelihood of Streptococcal pharyngitis; ${ }^{3}$ the CAGE score, which serves as a screening test 
for alcoholism; ${ }^{4}$ and the CHADS2 score, which predicts the risk of stroke in patients with atrial fibrillation. ${ }^{5}$

CPRs integrated into electronic clinical decision support tools have demonstrated the ability to shape healthcare provider behaviour towards more evidencebased clinical practice. ${ }^{6}$ However, provider adoption continues to be a significant barrier to widespread use of clinical decision support as a whole, which is reported at 10-20\%. ${ }^{7}$ Efficiency, usefulness, information content, user interface and workflow have been reported by clinicians to be the keys to effective decision support. ${ }^{7}$ These are likely to be large determinants of clinician adoption rates.

In light of the growing interest in integrated clinical decision support, and CPRs in particular, this study sought to help address the biggest challenge of implementation, poor provider adoption. The study focuses on provider perceptions of usefulness of CPRs in an effort to illuminate preferences, attitudes and thoughts that might be relevant to all types of clinical decision support. We examine healthcare provider perceptions of usefulness based on specialty and level of training with the ultimate goal of discovering which CPRs might be better adopted by these providers.

\section{METHODS}

A web-based survey platform was distributed to 401 healthcare providers between 1 January and 31 May 2013 in two academic medical centres, Hofstra North Shore-LIJ School of Medicine and Boston University, in the USA.

The survey content and structure were informed by qualitative interviews with physicians, a literature review and feedback received after pilot testing. The survey was piloted for approximately 1 month and after minor modifications, for instruction clarity and reduced length, distributed via email to attending physicians, nurse practitioners and residents training in the fields of internal medicine (IM) and emergency medicine (EM).

Providers were included in this study if they were credentialed as medical doctors, doctors of osteopathy or nurse practitioners, and were currently employed in either the IM or EM departments at each institution. Providers were excluded if they were currently involved in the study.

Participants were recruited, consented and asked to complete the survey via email. Additionally, providers were approached during grand rounds and resident afternoon conferences to encourage them to complete the survey. Laptops with the survey preloaded were placed at meetings to encourage completion. In addition, providers were sent reminder emails twice a month throughout the study period.

The survey consisted of three distinct sections. In the first section, participants were asked for demographic information, including hospital affiliation, professional degree, current position (attending vs resident), percentage of time devoted to clinical responsibilities, primarily outpatient versus inpatient practice, years of practice, medical specialty, race, gender and age. Demographic information, including race and gender, was assessed to determine the extent to which findings could be generalised to other medical communities.

In the second section, providers were asked to pick from a list of 24 CPRs: National Emergency X-Radiography Utilization Study (NEXUS) C-Spine Rule, ${ }^{8}$ Canadian C-Spine Rule, ${ }^{9}$ Ottawa Knee Rule, ${ }^{10}$ Walsh, ${ }^{11}$ Lee Index,${ }^{12}$ The Thrombolysis in Myocardial Infarction (TIMI) Risk Score (NSTEMI) ${ }^{13}$ CHADS2, ${ }^{5}$ 4T Score for Heparin-Induced Thrombocytopenia (HIT), ${ }^{14}$ Ottawa Ankle Rule, ${ }^{15}$ Pulmonary Embolism Rule-Out Criteria (PERC), ${ }^{16}$ Wells Score for deep venous thrombosis (DVT). ${ }^{17}$ Wells Score for Pulmonary Embolism (PE), ${ }^{18}$ Alcohol Abuse CAGE, ${ }^{4}$ Model for End-Stage Liver Disease (MELD) Score ${ }^{19}$ San Francisco Rule for Syncope, ${ }^{20}$ Modified Early Warning System (MEWS), ${ }^{21}$ CURB 65, ${ }^{22}$ Ranson's Criteria, ${ }^{23}$ Pittsburgh Knee Rule, ${ }^{24}$ Predicting Tuberculosis (TB) in Patients, ${ }^{25}$ Pneumonia Severity Index (PSI)/Pneumonia Patient Outcomes Research Team (PORT) Score, ${ }^{26}$ Acute Physiology and Chronic Health Evaluation (APACHE II), ${ }^{27}$ Mortality in Emergency Department Sepsis (MEDS) ${ }^{28}$ and Ventilator Associated Pneumonia (VAP).$^{29}$ They were asked to select all of the CPRs that were familiar to them. Of those CPRs, participants were then asked to select three that they found most useful.

The last section of the survey applied only to those three CPRs. They were asked questions about their perception of the utility and favourability of the CPRs. Statements such as "The 4T score for Heparin-Induced Thrombocytopenia is easy to use" were rated on a Likert scale from 1 (strongly disagree) to 5 (strongly agree). The last question in this section asked the provider to rate the CPR on a 10-point scale in terms of overall usefulness.

\section{Statistical methods}

Descriptive statistics, such as means and SDs for continuous variables, and frequencies and proportions for categorical variables, were used to describe the respondent characteristics.

The $\chi^{2}$ test or Fisher's exact test, as appropriate, was used to explore the association between each of the categorical questionnaire items and the key variables of interest (eg, IM vs EM). The Mann-Whitney test was used to compare the target groups on the ordinal and continuous variables. Finally, the Spearman correlation was used to measure the correlation between selected ordinal variables and the usefulness of the CPR.

\section{RESULTS}

Of the 401 healthcare providers distributed the webbased survey, 22 individuals declined participation, 
111 respondents agreed to participate but did not finish the survey, 1 individual completed the survey but left the agreement field blank, and 4 individuals left the agreement field blank and did not finish the survey. A total of 263 individuals, $66 \%$ of those asked to participate, agreed to respond, provided written informed consent and completed the survey. No stipend was provided.

\section{Demographic characteristics}

The IM and EM groups were compared on a number of demographic characteristics (table 1). There were significant differences between the two groups in terms of the institution they represented. Whereas a greater proportion of IM respondents were from Hofstra North Shore-LIJ School of Medicine (77\% vs 63\%), a greater proportion of the EM respondents were from Boston University ( $37 \%$ vs $22 \% ; \mathrm{p}<0.01)$. Significant differences were also noted when comparing the IM and EM groups on position occupied. Attending physicians in EM were over-represented compared with IM attending physicians ( $54.2 \%$ vs $28 \%$, respectively; $\mathrm{p}<0.001)$.

Participants were diverse in terms of age, race and total years of practice. There was a male predominance $(61 \%)$, which paralleled that seen in national US physician data where only about one-third of medical doctors are women. ${ }^{30}$ Compared with national US physician data, our sample included slightly less Caucasians, $62 \%$ vs $75 \%$; and less African-Americans, $3.3 \%$ vs 6\%; and more Asian, $27 \%$ vs $12.8 \%$ physicians. The majority $(75 \%)$ of the physicians were between 25 and 39 years of age, and had nine or fewer years of practice.

\section{Most familiar and most useful CPRs}

Participants were asked to select an unlimited number of CPRs that they were familiar with and of those choose three they felt were the most useful (table 2). The Alcohol Abuse CAGE, ${ }^{4}$ CHADS2, ${ }^{5}$ TIMI Score (NSTEMI) ${ }^{13}$ and Wells Score for $\mathrm{PE}^{18}$ were in the top five most frequently chosen as familiar and useful. Ranson's criteria ${ }^{23}$ was one of the top five most selected as familiar but not as useful and vice versa for the MELD score. ${ }^{19}$ The CHADS2 ${ }^{5}$ score was chosen as most useful by most participants $(63 \%)$.

When the list of CPRs most frequently selected as most useful is evaluated by specialty, the rankings diverge. EM providers were more likely to choose CPRs commonly used in emergency departments like PERC, ${ }^{16}$ NEXUS C-Spine Rule, ${ }^{8}$ Ottawa Ankle Rule ${ }^{15}$ and Canadian C-Spine. ${ }^{9}$ IM providers were more likely to choose CPRs commonly used on inpatient services like CHADS2, ${ }^{5}$ TIMI score (NSTEMI), ${ }^{13}$ Alcohol $\mathrm{CAGE}^{4}$ and MELD. ${ }^{19}$ Of note, both lists for CPRs rated as most useful included the Wells Score for PE. ${ }^{18}$

\section{EM versus IM healthcare provider perceptions of CPRs}

Providers were then asked specific questions about each of the three CPRs they rated as most useful. EM providers, compared with IM providers, rated their CPRs significantly more positively as having a better fit into their workflow $(\mathrm{p}=0.004)$, helping more with decisionmaking $(\mathrm{p}=0.037)$ and better fitting into their thought process when diagnosing patients $(p=0.001)$ (table 3$)$. There was a trend observed, although not meeting statistical significance, where EM providers consistently reported higher Likert scores for positive CPR qualities, such as easy to use, and IM providers consistently reported higher Likert scores for negative CPR qualities, such as limits independent decision. Lastly, compared with IM providers, EM providers rated their CPRs on a 10-point scale as overall significantly more useful $(\mathrm{p}=0.009)$.

\section{Specific CPR overall usefulness score by provider type}

The overall usefulness score was considered to be the ultimate indicator of strength of provider preference for the CPR. Scores for each CPR's usefulness were compared across provider specialty, resident versus attending position, and primary outpatient versus inpatient practice.

The only CPR with a significant difference between usefulness scores between specialties was the Ottawa Ankle Rule ${ }^{15}$ and the Wells Score for PE, ${ }^{18}$ both preferred by providers in EM. Of note, many of the 24 CPRs could not be compared by specialty because these were not selected by any EM providers as one of the top three most useful, including the $4 \mathrm{~T}$ Score for HIT, ${ }^{14}$ APACHE II, ${ }^{27}$ Lee Index,${ }^{12}$ MELD,${ }^{19}$ MEWS,${ }^{21}$ Predicting TB,${ }^{25}$ Ranson's, ${ }^{23}$ Ventilator Associated Pneumonia ${ }^{29}$ and MEDS. $^{28}$

Two differences were observed between usefulness scores of providers working in mostly or all inpatient versus outpatient settings. Inpatient providers rated the $4 \mathrm{~T}$ Score for $\mathrm{HIT}^{14}$ as significantly more useful, while providers working in mostly or all outpatient settings rated the Walsh score ${ }^{11}$ as significantly more useful. There were no differences between resident versus attending ratings of overall usefulness for any CPR.

\section{CPR characteristics and overall usefulness score}

Ratings for perceived qualities of each CPR were analysed in terms of their correlation with usefulness score (table 4). For all providers, EM and IM, the perceived qualities of being useful at point of care and helps with decision-making, saves time in diagnosing, fits into one's thought process, and should be the standard of clinical care correlated highly $(\geq 0.65)$ with usefulness scores.

\section{DISCUSSION}

Perceived utility of clinical decision support tools and clinical guidelines have been previously studied; ${ }^{31} 32$ however, this is the first study to examine healthcare provider perception of usefulness of CPRs in the hospital setting. Providers surveyed in this study reported clear 
Table 1 Demographics of survey participants

\begin{tabular}{|c|c|c|c|c|}
\hline & $\begin{array}{l}\text { Total } \\
\mathrm{N}=298\end{array}$ & $\begin{array}{l}\text { Internal medicine } \\
\mathrm{N}=215(72 \%)\end{array}$ & $\begin{array}{l}\text { Emergency medicine } \\
\mathrm{N}=83(28 \%)\end{array}$ & p Value \\
\hline Institution & & & & 0.01 \\
\hline Hofstra North Shore-LIJ School of Medicine & $176(59 \%)$ & 137 & 39 & \\
\hline Boston University & $119(40 \%)$ & 75 & 44 & \\
\hline Other & $3(1 \%)$ & 3 & 0 & \\
\hline Degree & & & & 0.22 \\
\hline Medical degree & $274(92 \%)$ & 199 & 75 & \\
\hline Doctor of osteopathy & $20(7 \%)$ & 12 & 8 & \\
\hline Nurse practitioner & $4(1 \%)$ & 4 & 0 & \\
\hline Role & & & & $<0.0001$ \\
\hline Attending & $105(35 \%)$ & 60 & 45 & \\
\hline Hospitalist & $16(5 \%)$ & 16 & 0 & \\
\hline House staff & $167(56 \%)$ & 129 & 38 & \\
\hline Nurse practitioner & $5(2 \%)$ & 5 & 0 & \\
\hline Other & $5(2 \%)$ & 5 & 0 & \\
\hline Practice location & & & & $<0.0001$ \\
\hline All outpatient & $69(23 \%)$ & 38 & 31 & \\
\hline Mostly outpatient & $31(11 \%)$ & 22 & 9 & \\
\hline Equal & $15(5 \%)$ & 11 & 4 & \\
\hline Mostly inpatient & $124(42 \%)$ & 117 & 7 & \\
\hline All inpatient & 57 (19\%) & 26 & 31 & \\
\hline Years of practice & & & & 0.06 \\
\hline $1-4$ & $183(61.4 \%)$ & 140 & 43 & \\
\hline $5-9$ & $43(14.4 \%)$ & 23 & 20 & \\
\hline $10-14$ & $22(7.4 \%)$ & 16 & 6 & \\
\hline $15-20$ & $21(7 \%)$ & 15 & 6 & \\
\hline$>20$ & $29(9.7 \%)$ & 21 & 8 & \\
\hline Age (years) & & & & 0.34 \\
\hline $25-29$ & $108(36 \%)$ & 85 & 23 & \\
\hline 30-39 & $116(39 \%)$ & 76 & 40 & \\
\hline $40-49$ & $44(15 \%)$ & 31 & 13 & \\
\hline $50-59$ & $20(7 \%)$ & 16 & 4 & \\
\hline $60-69$ & $6(2 \%)$ & 4 & 2 & \\
\hline $70+$ & $4(1 \%)$ & 3 & 1 & \\
\hline Race (may select $>1$ ) & & & & NA \\
\hline Caucasian & $185(62 \%)$ & 119 & 66 & \\
\hline African-American & $10(3.3 \%)$ & 8 & 2 & \\
\hline Asian & $80(27 \%)$ & 71 & 9 & \\
\hline Hispanic & $11(3.8 \%)$ & 7 & 4 & \\
\hline Native American & $1(0.3 \%)$ & 1 & 0 & \\
\hline Other & $11(3.7 \%)$ & 8 & 3 & \\
\hline Gender & & & & 0.38 \\
\hline Female & $117(39 \%)$ & 88 & 29 & \\
\hline Male & $180(61 \%)$ & 127 & 53 & \\
\hline
\end{tabular}

preferences for certain CPRs. Participants consistently rated CHADS2, ${ }^{5}$ TIMI Score (NSTEMI), ${ }^{13}$ Wells Score for PE, ${ }^{18}$ Alcohol Abuse $\mathrm{CAGE}^{5}$ and the Ottawa Ankle Rule ${ }^{15}$ highly. These CPRs would be ideal candidates for integration into an electronic health record (EHR).

Interestingly, EM providers consistently rated their chosen CPRs more positively. We found as well that qualities like ease of use, saves time, helps with decisionmaking, and should be standard of clinical care had a strong relationship to providers' perception of utility. These qualities should be considered as requirements for a CPR considered for integration into an electronic health record.

Improved clinical care as well as decreased costs and decreased waste are potential results of provider preferred integrated CPRs. Although the USA spends nearly double the average, $\$ 3923$, of all of the Organisation for Economic Co-operation and Development (OECD) 
Table 2 All 24 CPRs, frequency of selection as familiar and top 3 most useful, ordered by mean 10-point usefulness score

\begin{tabular}{|c|c|c|c|}
\hline All 24 CPRs & $\begin{array}{l}\text { Familiar } \\
\mathrm{N}(\%)\end{array}$ & $\begin{array}{l}\text { Useful } \\
\mathrm{N}(\%)\end{array}$ & $\begin{array}{l}\text { Useful score } \\
\text { mean }\end{array}$ \\
\hline $\begin{array}{l}\text { NEXUS C-Spine Rule } \\
\text { Imaging in patients at risk for c-spine fracture }\end{array}$ & $14(4.6)$ & $33(11)$ & 8.54 \\
\hline $\begin{array}{l}\text { Canadian C-Spine Rule } \\
\text { Imaging in patients at risk for } c \text {-spine fracture }\end{array}$ & 85 (29) & $28(9)$ & 8.5 \\
\hline $\begin{array}{l}\text { Ottawa Knee Rule } \\
\text { Imaging in patients with knee trauma }\end{array}$ & $77(26)$ & $9(3)$ & 8.5 \\
\hline $\begin{array}{l}\text { Walsh } \\
\text { Likelihood of Streptococcal pharyngitis }\end{array}$ & $110(37)$ & 27 (9) & 8.39 \\
\hline $\begin{array}{l}\text { Lee Index }{ }^{12} \\
\text { Perioperative cardiovascular risk }\end{array}$ & $30(10)$ & $10(3)$ & 8.38 \\
\hline $\begin{array}{l}\text { TIMI Score (NSTEMI) })^{13} \\
\text { Mortality in patients with NSTEMI }\end{array}$ & $253(85)$ & $89(30)$ & 8.12 \\
\hline $\begin{array}{l}\text { CHADS }^{5} \\
\text { Stroke risk in patients with atrial fibrillation }\end{array}$ & $255(86)$ & $184(62)$ & 8.01 \\
\hline $\begin{array}{l}\text { 4T Score for } \mathrm{HIT}^{14} \\
\text { Likelihood of HIT }\end{array}$ & $76(26)$ & $19(6)$ & 7.91 \\
\hline $\begin{array}{l}\text { Ottawa Ankle Rule }{ }^{15} \\
\text { Imaging in patients with ankle trauma }\end{array}$ & $170(57)$ & $55(18)$ & 7.84 \\
\hline $\begin{array}{l}\text { PERC }^{16} \\
\text { Rules out pulmonary embolism }\end{array}$ & $78(26)$ & $38(13)$ & 7.84 \\
\hline $\begin{array}{l}\text { Wells Score for DVT } \\
\text { Estimates likelihood of DVT }\end{array}$ & $212(71)$ & $43(14)$ & 7.48 \\
\hline $\begin{array}{l}\text { Wells Score for } \mathrm{PE}^{18} \\
\text { Calculates risk of pulmonary embolism }\end{array}$ & $232(78)$ & $82(28)$ & 7.29 \\
\hline $\begin{array}{l}\text { Alcohol Abuse CAGE } \\
\text { Screen for alcohol abuse }\end{array}$ & $271(91)$ & $64(21)$ & 7.27 \\
\hline $\begin{array}{l}\text { MELD }{ }^{19} \\
\text { Estimates mortality in end-stage liver disease }\end{array}$ & $211(71)$ & $56(19)$ & 7.26 \\
\hline $\begin{array}{l}\text { San Francisco Rule for Syncope } \\
\text { Risk stratification of patients with syncope }\end{array}$ & $62(21)$ & $10(3)$ & 7.22 \\
\hline $\begin{array}{l}\text { MEWS }^{21} \\
\text { Identifies clinically deteriorating patients }\end{array}$ & $96(32)$ & 7 (2) & 7 \\
\hline $\begin{array}{l}\text { CURB } 65^{22} \\
\text { Mortality in patients with pneumonia }\end{array}$ & $192(64)$ & $41(14)$ & 6.88 \\
\hline $\begin{array}{l}\text { Ranson's Criteria }{ }^{23} \\
\text { Mortality in patients with pancreatitis }\end{array}$ & $262(88)$ & $33(11)$ & 6.53 \\
\hline $\begin{array}{l}\text { Pittsburgh Knee Rule } \\
\text { Imaging in patients with knee trauma }\end{array}$ & $17(6)$ & $2(1)$ & 6.5 \\
\hline $\begin{array}{l}\text { Other (please list) } \\
\text { Predicting TB in Patients }\end{array}$ & $\begin{array}{l}19(6) \\
15(5)\end{array}$ & $\begin{array}{l}6(2) \\
1(0)\end{array}$ & $\begin{array}{l}6.33 \\
6\end{array}$ \\
\hline $\begin{array}{l}\text { Predicts likelihood of tuberculosis } \\
\text { PSI/PORT Score }\end{array}$ & $148(50)$ & $18(6)$ & 5.83 \\
\hline $\begin{array}{l}\text { Mortality in patients with pneumonia } \\
\text { APACHE } \|^{27} \\
\text { Estimates mortality in ICU patients }\end{array}$ & $193(65)$ & $12(4)$ & 5.8 \\
\hline $\begin{array}{l}\text { MEDS }^{28} \\
\text { Estimates mortality in septic ED patients }\end{array}$ & $100(34)$ & $6(2)$ & NA \\
\hline $\begin{array}{l}\text { VAP }^{29} \\
\text { Predicts risk of VAP }\end{array}$ & $48(16)$ & $2(1)$ & NA \\
\hline
\end{tabular}

countries $^{33}$ on healthcare, American patients receive about $55 \%$ of recommended clinical care. ${ }^{34}$ Overtreatment and failures in execution of care processes are partially responsible for waste in healthcare spending, estimated as exceeding 20\%. ${ }^{35}$ Meta-analysis of the effect of clinical decision support has shown that 
Table 3 Mean ratings of all chosen CPRs by EM versus IM

\begin{tabular}{llll}
\hline CPR characteristic & $\begin{array}{l}\text { EM } \\
\text { mean (SD) }\end{array}$ & $\begin{array}{l}\text { IM } \\
\text { mean (SD) }\end{array}$ & p Value \\
\hline Easy to use & $3.93(1.04)$ & $3.77(1.00)$ & 0.112 \\
Useful at point of care & $3.94(1.03)$ & $3.78(1.01)$ & 0.141 \\
Currently look-up electronically & $2.98(1.21)$ & $2.91(1.17)$ & 0.583 \\
Would use if electronic & $3.49(1.18)$ & $3.57(1.13)$ & 0.659 \\
Fits into workflow & $3.92(1.06)$ & $3.65(0.99)$ & 0.004 \\
Helps with decision-making & $3.96(1.07)$ & $3.79(0.98)$ & 0.037 \\
Saves time diagnosing & $3.50(1.05)$ & $3.33(1.01)$ & 0.088 \\
Limits independent decision & $1.96(0.82)$ & $2.12(0.88)$ & 0.242 \\
Patient too complex to use CPR & $2.05(0.77)$ & $2.25(0.83)$ & 0.118 \\
Fits into thought process & $3.85(1.03)$ & $3.63(0.94)$ & 0.001 \\
Many colleagues use & $3.61(1.01)$ & $3.54(0.96)$ & 0.572 \\
Should be standard clinical care & $3.52(1.02)$ & $3.57(0.97)$ & 0.588 \\
Overall usefulness scale & $7.43(1.87)$ & $6.84(2.03)$ & 0.009 \\
\hline CPR, clinical prediction rule; EM, emergency medicine; IM, internal medicine. & &
\end{tabular}

Table 4 Correlations between CPR characteristics and the overall usefulness rating

\begin{tabular}{llll}
\hline CPR characteristic & $\begin{array}{l}\text { Emergency } \\
\text { medicine }\end{array}$ & $\begin{array}{l}\text { Internal } \\
\text { medicine }\end{array}$ & p Value \\
\hline Easy to use & 0.734 & 0.581 & 0.07 \\
Useful at POC & 0.767 & 0.681 & 0.219 \\
Currently look-up electronically & 0.267 & 0.383 & 0.379 \\
Would use if electronic & 0.480 & 0.656 & 0.077 \\
Fits into workflow & 0.768 & 0.634 & 0.072 \\
Helps with decision-making & 0.763 & 0.677 & 0.222 \\
Saves time diagnosing & 0.704 & 0.660 & 0.569 \\
Limits independent decision & 0.200 & 0.188 & 0.936 \\
Patient too complex to use CPR & 0.074 & 0.165 & 0.535 \\
Fits into thought process & 0.725 & 0.668 & 0.453 \\
Many colleagues use & 0.630 & 0.556 & 0.435 \\
Should be standard clinical care & 0.778 & 0.748 & 0.631 \\
\hline CPR, clinical prediction rule; POC, point of care. & & &
\end{tabular}

providers with decision support were more likely to provide preventive care services and order appropriate treatments. ${ }^{7}$

\section{Limitations}

A significant limitation of the results of this study is that mean ratings for CPR characteristics reflect only the opinion of healthcare providers who selected the CPR as one of the top three most useful. However, the structure of the survey also ensures that CPR characteristic ratings were made only by providers who were likely to use the CPR in daily practice.

Additionally, participants were recruited during academic conferences, including grand rounds as well as afternoon conferences for residents. This may have increased the number of participants who attend academic conferences, and who are more familiar with CPRs.

\section{Implications for clinical practice and research}

Meaningful clinical decision support requires not just understanding healthcare provider perceptions, but also choosing tools that are strongly evidence-based and have been tested for their effectiveness. Future trials should focus on evaluating the clinical impact of healthcare provider preferred CPRs.

\section{CONCLUSION}

Healthcare providers describe clear preferences for certain characteristics and disease-specific CPRs. EM providers consistently rated CPRs more positively and may serve as early adapters for CPRs integrated into EHRs. Understanding provider perceptions may help to address limiting factors in meaningful integration of clinical decision support into our electronic health systems.

Acknowledgements The authors would like to acknowledge the contributions of Megan Knaus, research coordinator affiliated with Hofstra North ShoreLIJ who helped in survey development and Dr Ambili Ramachandran, Internal Medicine resident affiliated with Boston University, who led data collection at that site. The abstract from this work was previously presented as a poster at the EDM Forum Symposium in San Diego California on 7 June 2014.

Collaborators Ambili Ramachandran, Megan Knaus.

Contributors TM and DM were involved in study concept and design, critical revision of the manuscript for important intellectual content and study 
supervision. SR was involved in acquisition of data. SR, TM, LM, SK and MK were involved in analysis and interpretation of data and drafting of the manuscript. SR, SK, LM and MK were involved in statistical analysis. LM and SK were involved in administrative, technical and material support.

Competing interests None declared.

Ethics approval North Shore-LIJ Health System IRB.

Provenance and peer review Not commissioned; externally peer reviewed.

Data sharing statement Additional data can be accessed by emailing MK, Associate Research Statistician, Biostatistics Unit, Feinstein Institute for Medical Research, North Shore-LIJ Health System.

Open Access This is an Open Access article distributed in accordance with the Creative Commons Attribution Non Commercial (CC BY-NC 4.0) license which permits others to distribute, remix, adapt, build upon this work noncommercially, and license their derivative works on different terms, provided the original work is properly cited and the use is non-commercial. See: http:// creativecommons.org/licenses/by-nc/4.0/

\section{REFERENCES}

1. Evidence-Based Medicine Working Group. Evidence-based medicine. A new approach to teaching the practice of medicine. JAMA 1992;268:2420-5.

2. Laupacis $\mathrm{A}$, Sekar N. Clinical prediction rules: a review and suggested modifications of methodological standards. JAMA 1997;277:488-94.

3. Centor RM, Witherspoon JM, Dalton HP, et al. The diagnosis of strep throat in adults in the emergency room. Med Decis Making 1980;1:239-46

4. Ewing JA. Detecting alcoholism: the CAGE questionnaire. JAMA 1984;252:1905-7.

5. Gage BF, Waterman AD, Shannon W, et al. Validation of clinical classification schemes for predicting stroke: results from the National Registry of Atrial Fibrillation. JAMA 2001;285:2864-70.

6. McGinn TG, McCullagh L, Kannry J, et al. Efficacy of an evidence-based clinical decision support in primary care practices: a randomized clinical trial. JAMA Intern Med 2013:173:1584-91.

7. Bright TJ, Wong A, Dhurjati R, et al. Effect of clinical decision-support systems: a systematic review. Ann Intern Med 2012;157:29-43.

8. Hoffman JR, Wolfson AB, Todd K, et al. Selective cervical spine radiography in blunt trauma: methodology of the National Emergency X-Radiography Utilization Study (NEXUS). Ann Emerg Med 1998;32:461-9.

9. Stiell IG, Wells GA, Vandemheen KL, et al. The Canadian C-spine rule for radiography in alert and stable trauma patients. JAMA 2001;286:1841-8.

10. Stiell IG, Wells GA, Hoag RH, et al. Implementation of the Ottawa Knee Rule for the use of radiography in acute knee injuries. JAMA 1997;278:2075-9.

11. Walsh BT, Bookheim WW, Johnson RC, et al. Recognition of streptococcal pharyngitis in adults. Arch Intern Med 1975;135:1493-7.

12. Boersma E, Kertai MD, Schouten O, et al. Perioperative cardiovascular mortality in noncardiac surgery: validation of the Lee cardiac risk index. Am J Med 2005;118:1134-41.

13. Antman EM, Cohen M, Bernink PJ, et al. The TIMI risk score for unstable angina/non-ST elevation MI: a method for prognostication and therapeutic decision making. JAMA 2000;284:835-42.
14. Lo G, Juhl D, Warkentin T, et al. Evaluation of pretest clinical score (4 T's) for the diagnosis of heparin-induced thrombocytopenia in two clinical settings. J Thromb Haemost 2006;4:759-65.

15. Stiell IG, Greenberg GH, McKnight RD, et al. A study to develop clinical decision rules for the use of radiography in acute ankle injuries. Ann Emerg Med 1992;21:384-90.

16. Kline J, Mitchell A, Kabrhel C, et al. Clinical criteria to prevent unnecessary diagnostic testing in emergency department patients with suspected pulmonary embolism. J Thromb Haemost 2004;2:1247-55.

17. Wells PS, Anderson DR, Bormanis J, et al. Value of assessment of pretest probability of deep-vein thrombosis in clinical management. Lancet 1997;350:1795-8.

18. Wells PS, Anderson DR, Rodger M, et al. Derivation of a simple clinical model to categorize patients probability of pulmonary embolism-increasing the models utility with the SimpliRED D-dimer. Thromb Haemost 2000;83:416-20.

19. Kamath PS, Wiesner $\mathrm{RH}$, Malinchoc $\mathrm{M}$, et al. A model to predict survival in patients with end-stage liver disease. Hepatology 2001;33:464-70.

20. Quinn J, McDermott D, Stiell I, et al. Prospective validation of the San Francisco Syncope Rule to predict patients with serious outcomes. Ann Emerg Med 2006;47:448-54.

21. Morgan R, Williams F, Wright M. An early warning scoring system for detecting developing critical illness. Clin Intensive Care 1997;8:100.

22. Lim W, Van der Eerden M, Laing R, et al. Defining community acquired pneumonia severity on presentation to hospital: an international derivation and validation study. Thorax 2003;58:377-82.

23. Ranson J. Prognostic signs and the role of operative management in acute pancreatitis. Surg Gynecol Obstet 1974;139:69-81.

24. Seaberg DC, Jackson R. Clinical decision rule for knee radiographs. Am J Emerg Med 1994;12:541-3.

25. Wisnivesky JP, Kaplan J, Henschke C, et al. Evaluation of clinical parameters to predict Mycobacterium tuberculosis in inpatients. Arch Intern Med 2000;160:2471-6.

26. Fine MJ, Auble TE, Yealy DM, et al. A prediction rule to identify low-risk patients with community-acquired pneumonia. $N$ Engl $\mathrm{J} \mathrm{Med}$ 1997;336:243-50.

27. Knaus WA, Draper EA, Wagner DP, et al. APACHE II: a severity of disease classification system. Crit Care Med 1985;13: 818-29.

28. Carpenter CR, Keim SM, Upadhye S, et al. Group BEiEMI. Risk stratification of the potentially septic patient in the emergency department: the Mortality in the Emergency Department Sepsis (MEDS) score. J Emerg Med 2009;37:319-27.

29. Klompas M. Does this patient have ventilator-associated pneumonia? JAMA 2007;297:1583-93.

30. Castillo-Page L. Diversity in the physician workforce: facts \& figures 2010. Association of American Medical Colleges, 2010:1-115.

31. Davis F. Perceived usefulness, perceived ease of use, and user acceptance of information technology. MIS Q 1989;13:319-40.

32. Putzer GJ, Park Y. Are physicians likely to adopt emerging mobile technologies? Attitudes and innovation factors affecting smartphone use in the Southeastern United States. Perspect Health Inf Manag 2012;9:1b.

33. Squires DA. The US health system in perspective: a comparison of twelve industrialized nations. Issue Brief (Commonw Fund) 2011;16:1-14

34. McGlynn EA, Asch SM, Adams J, et al. The quality of health care delivered to adults in the United States. $N$ Engl J Med 2003;348:2635-45.

35. Berwick DM, Hackbarth AD. Eliminating waste in US health care JAMA 2012;307:1513-16. 